\title{
Neurokinin-1 Receptor-Expressing Cells of the Ventral Respiratory Group Are Functionally Heterogeneous and Predominantly Glutamatergic
}

\author{
Patrice G. Guyenet, Charles P. Sevigny, Matthew C. Weston, and Ruth L. Stornetta \\ Department of Pharmacology, University of Virginia, Charlottesville, Virginia 22908
}

According to a recent theory (Gray et al., 1999) the neurokinin-1 receptor (NK1R)-immunoreactive (ir) neurons of the ventral respiratory group (VRG) are confined to the pre-Bötzinger complex (pre-BötC) and might be glutamatergic interneurons that drive respiratory rhythmogenesis. In this study we tested whether the NK1R-ir neurons of the VRG are glutamatergic. We also examined whether different groups of NK1R-ir neurons coexist in the VRG on the basis of whether these cells contain preproenkephalin (PPE) mRNA or project to the spinal cord.

NK1R immunoreactivity was found in two populations of VRG neurons that are both predominantly glutamatergic because most of them contained vesicular glutamate transporter 2 mRNA $(77 \pm 9 \% ; n=3)$. A group of small fusiform neurons (somatic cross section: $91 \pm 3.6 \mu \mathrm{m}^{2}$ ) that has neither PPE mRNA nor spinal projections is primarily restricted to the preBötC. These cells may be the interneurons the destruction of which produces massive disruptions of the respiratory rhythm (Gray et al., 2001). The rest of the NK1R-ir neurons of the VRG are multipolar, are larger (somatic cross section: $252 \pm 15$ $\mu \mathrm{m}^{2}$ ), and express high levels of PPE mRNA. Some of these cells located in the rostral half of the rostral VRG project to the spinal cord (C4 or T3). Using electrophysiological methods, we showed that these bulbospinal NK1R-ir neurons are slowly discharging inspiratory-augmenting neurons, suggesting that they may control phrenic or intercostal motor neurons.

In summary, NK1R-expressing cells of the VRG are a heterogeneous group of predominantly glutamatergic neurons that include subpopulations of respiratory premotor neurons.

Key words: pre-Bötzinger complex; respiration; respiratory rhythm generation; vesicular glutamate transporters; VGLUT2; substance $P$; opioid peptides; preproenkephalin; premotor neurons
The pre-Bötzinger complex (pre-BötC) contains a distinctive mix of propriomedullary neurons with respiratory discharges (Ellenberger and Feldman, 1990; Connelly et al., 1992; Dobbins and Feldman, 1994; Schwarzacher et al., 1995). Acidification or chemical activation of the pre-BötC greatly increases respiratory rate, indicating that this restricted region of the ventral respiratory group (VRG) regulates or perhaps generates the respiratory rhythm (Chitravanshi and Sapru, 1999; Solomon et al., 1999, 2000). In neonate preparations in vitro, the pre-BötC is the source of a respiratory-like rhythm that is transmitted polysynaptically to hypoglossal or phrenic motor neurons (Smith et al., 1991; Feldman and McCrimmon, 1999). This periodic activity is driven by a kernel of glutamatergic neurons that includes cells with intrinsic bursting properties (Johnson et al., 1994; Butera et al., 1999a,b; Lieske et al., 2000; Rekling et al., 2000). The recently proposed hybrid-pacemaker network theory of respiration (Feldman and McCrimmon, 1999; Smith et al., 2000) postulates that rhythm generation in vivo might also be driven by this kernel of pre-BötC excitatory interneurons rather than by reciprocal interactions between sets of inhibitory neurons (Duffin et al., 1995).

The adult characteristics of the glutamatergic neurons that drive the respiratory-like rhythm of neonate brainstem prepara-

\footnotetext{
Received Dec. 26, 2001; revised Feb. 7, 2002; accepted Feb. 12, 2002.

This work was supported by National Institutes of Health Grants HL28785 and HL 60003 to P.G.G. We also thank Dr. Ryuichi Shigemoto (National Institute for Physiological Sciences, Myodaiji, Okazaki, Japan) for providing a sample of their antibody against the NK1 receptor.

Correspondence should be addressed to Dr. Patrice G. Guyenet, University of Virginia Health System, P.O. Box 800735, 1300 Jefferson Park Avenue, Charlottesville, VA 22908-0735. E-mail: pgg@virginia.edu.

Copyright () 2002 Society for Neuroscience $\quad 0270-6474 / 02 / 223806-11 \$ 15.00 / 0$
}

tions are unknown, although several lines of evidence suggest that these cells might be identifiable by their high level of expression of neurokinin-1 receptors (NK1Rs) (Gray et al., 1999, 2001). However, this theory is based on three basically undemonstrated assumptions: namely, the NK1R-immunoreactive (ir) cells of the adult VRG are glutamatergic neurons and confined to the preBötC, they are propriomedullary, and they are functionally homogeneous.

NK1R immunoreactivity is detectable in a subset of VRG neurons that are neither cholinergic nor catecholaminergic and generally lack markers of inhibitory transmission [glutamic acid decarboxylase 67 (GAD 67) and glycine transporter-2] (Liu et al., 2001; Pilowsky and Feldman, 2001; H. Wang et al., 2001). A major alternative left by elimination is that the NK1R-ir cells of the VRG are glutamatergic (H. Wang et al., 2001). To address this question directly we tested in the present study whether the NK1R-ir cells of the VRG contain the mRNA that encodes vesicular glutamate transporter 2 (VGLUT2) (Aihara et al., 2000; Bai et al., 2001; Fremeau et al., 2001). VGLUT2 is a diagnostic marker of glutamatergic neurons (Fremeau et al., 2001), especially in the cardiorespiratory portion of the brainstem reticular formation (Stornetta et al., 2002a).

To determine whether VRG NK1R-ir cells are a functionally homogeneous population, we analyzed the pattern of expression of another marker, preproenkephalin (PPE) mRNA and found that this marker is associated with two morphologically different types of VRG NK1R-ir neurons. To test whether the NK1Rexpressing cells are confined to the Pre-BötC and exclusively propriomedullary, we examined whether any of them project to the cervical and thoracic cord. Having confirmed that some of 
them are bulbospinal (H. Wang et al., 2001), we tested whether these bulbospinal NK1R-ir neurons could be some form of respiratory premotor neuron.

\section{MATERIALS AND METHODS}

All experiments were performed on male Sprague Dawley rats (250-350 gm; Hilltop Laboratories, Scotsdale, PA) in accordance with National Institutes of Health and institutional animal care and use guidelines. All procedures and protocols were approved by the University of Virginia's Animal Research Committee.

Recording and juxtacellular labeling of rostral VRG bulbospinal inspiratory neurons. Anesthesia was induced with 5\% halothane in $100 \%$ oxygen. During surgery, the rats $(n=9)$ were artificially ventilated with $1.6-1.8 \%$ halothane in $100 \%$ oxygen via a tracheal cannula $(50-60$ cycles/min; $1-1.2 \mathrm{ml} / 100 \mathrm{gm})$. End-expiratory $\mathrm{CO}_{2}$ was maintained between 4.5 and $5 \%$ during surgery, and rectal temperature was kept between 37.5 and $38.5^{\circ} \mathrm{C}$. A femoral artery and a vein were catheterized to record arterial blood pressure (AP) and to administer drugs, respectively. The rats were placed in a stereotaxic frame, and the right phrenic nerve was isolated as described previously (Guyenet and Wang, 2001). A concentric bipolar stimulating electrode (Rhodes Medical Instruments, Woodland, CA; diameter $250 \mu \mathrm{m}$; tip separation $500 \mu \mathrm{m}$ ) was placed in the fascia surrounding the mandibular branch of the left facial nerve to elicit antidromic field potentials in the facial motor nucleus (Schreihofer and Guyenet, 1997). A second bipolar electrode was inserted into the left lower quadrant of spinal segment $\mathrm{C} 4$ and used to test for spinal axonal projections of neurons recorded in the rostral VRG (monophasic square pulses; $100 \mu \mathrm{sec}$ duration; 50-400 $\mu \mathrm{A}$ intensity).

After completion of surgery, halothane was turned off and replaced by urethane administered intravenously to a final dose of $1 \mathrm{gm} / \mathrm{kg}$. This dose was sufficient to maintain anesthesia at a level at which a strong pinch of the tail or hindpaw produced no retraction and no change in arterial pressure or phrenic nerve discharge (PND). After $45 \mathrm{~min}$, the muscle relaxant pancuronium was administered $(1 \mathrm{mg} / \mathrm{kg}$, i.v., with $0.3-0.5 \mathrm{mg} / \mathrm{kg}$ supplements as required), ventilation was adjusted so that end-expiratory $\mathrm{CO}_{2}$ was $\sim 1 \%$ above the threshold of the phrenic discharge $(\sim 5.5 \%)$, and electrophysiological recordings were initiated. Under paralysis, the adequacy of the anesthesia was gauged by the lack of effect of the above-mentioned nociceptive stimuli on AP and PND rate or amplitude. Additional urethane $(0.2 \mathrm{gm} / \mathrm{kg})$ was administered as needed. During the recording period, the mean AP of the rats was between 125 and $140 \mathrm{mmHg}$.

PND (bipolar recordings, 200-3000 Hz) was full-wave rectified and filtered (Guyenet and Wang, 2001). Unit activity was recorded with glass electrodes filled with $0.5 \mathrm{~m}$ sodium acetate containing $1.5 \%$ biotinamide (MW 367.3; Molecular Probes, Eugene, OR), pH 4.5, using an intracellular amplifier in bridge mode (Axoclamp 2A), and the signal was further processed through an $\mathrm{AC}$ amplifier $(100 \times$ gain; $0.2-3 \mathrm{kHz}$ bandpass; 60 $\mathrm{Hz}$ notch filter).

The region of the rostral VRG (rVRG) was determined in each rat with reference to the location of the caudal pole of the facial motor nucleus. Our previous experiments have suggested that the pre-BötC is centered $\sim 0.8 \mathrm{~mm}$ behind the facial motor nucleus $(0.6-1.1 \mathrm{~mm})$ (Guyenet and Wang, 2001; H. Wang et al., 2001). Inspiratory augmenting neurons beyond $1.2 \mathrm{~mm}$ caudal to the facial motor nucleus predominate, suggesting that this region corresponds to the rVRG. The latter region (1.2-1.5 mm caudal to the facial motor nucleus) was selectively targeted in the present study to record from putative bulbospinal inspiratory premotor neurons. The classification of respiratory neurons was based on the timing of their discharge in relation to that of the phrenic nerve using accepted nomenclature (Schwarzacher et al., 1995; Feldman and McCrimmon, 1999).

Recorded neurons were individually filled with biotinamide using the juxtacellular labeling method (Pinault, 1996; Schreihofer and Guyenet, 1997; Schreihofer et al., 1999). The activity of the unit was monitored during the entire labeling procedure ( $30 \mathrm{sec}$ to $2 \mathrm{~min}$ ) to insure that only one recorded cell was being entrained.

All physiological variables (AP, end-expiration $\mathrm{CO}_{2}, \mathrm{PND}$, integrated PND, and unit activity) were monitored and stored on a PC with a Power 1401 interface and version 3 of the Spike2 software (both from Cambridge Electronics Design Ltd., Cambridge, UK). Analog signals were sampled at $11,120 \mathrm{~Hz}$ for spikes, $4600 \mathrm{~Hz}$ for PND, and $100 \mathrm{~Hz}$ for AP, integrated PND, and end-expiratory $\mathrm{CO}_{2}$. Action potential frequency was measured by binning spikes into $50 \mathrm{msec}$ intervals. To make the final illustrations, representative excerpts of the Spike2 data files were exported into a drawing program (Canvas 6, Deneba, Miami, FL).

After juxtacellular labeling of two to four rVRG inspiratory neurons, the rats were deeply anesthetized with $4 \%$ halothane in $100 \% \mathrm{O}_{2}$. They were then perfused through the ascending aorta with $250 \mathrm{ml}$ of PBS, $\mathrm{pH}$ 7.4, followed by $4 \%$ phosphate-buffered $(0.1 \mathrm{M}), \mathrm{pH} 7.35)$ paraformaldehyde (Electron Microscopy Sciences, Fort Washington, PA). The brainstem was removed and stored in the same fixative overnight at $4^{\circ} \mathrm{C}$. Series of coronal sections $(30 \mu \mathrm{m})$ were cut through the medulla using a vibrating microtome and stored in cryoprotectant solution at $20^{\circ} \mathrm{C}$ for up to 2 weeks $(20 \%$ glycerol plus $30 \%$ ethylene glycol in $50 \mathrm{~mm}$ phosphate buffer, $\mathrm{pH}$ 7.4) until histological processing.

Injections of retrograde markers. In three rats anesthetized with a mixture of ketamine $(75 \mathrm{mg} / \mathrm{kg})$, xylazine $(5 \mathrm{mg} / \mathrm{kg})$, and acepromazine $(1 \mathrm{mg} / \mathrm{kg})$ administered intramuscularly, the retrograde marker FluoroGold (FG; Fluorochrome, Inc., Englewood, CO) (Schmued and Fallon, 1986) was injected iontophoretically into the left ventral horn of spinal segment $\mathrm{C} 4$. Two to four penetrations with a recording electrode were used to identify the phrenic motor nucleus, and then the recording electrode was withdrawn and a micropipette filled with $3 \%$ FG in $0.9 \%$ $\mathrm{NaCl}$ was inserted in its place. Fluoro-Gold was ejected by iontophoresis ( $5 \mathrm{sec}$ pulses; $50 \%$ duty cycle; $5 \mu \mathrm{A}$ positive current; $20 \mathrm{~min}$ ) using a constant current source. Two more rats received pressure injections of FG into segment C4 (six sites, three on each side; $40 \mathrm{nl}$ per site; $2 \%$ FG in normal saline). These injections were targeted at the ventral horn (1 $\mathrm{mm}$ from midline, $1.6 \mathrm{~mm}$ below dorsal surface) and separated by $1 \mathrm{~mm}$ in the rostrocaudal direction. Finally, two more rats received pressure injections of FG into segment T3 (same volume), also targeted at the ventral horn (lateral $0.7 \mathrm{~mm}$; depth $1.3 \mathrm{~mm}$ ). In the four rats subjected to pressure injections of FG, a 2- to 3-mm-long necrotic center was observed at the injection site, and intense FG fluorescence extended over approximately two spinal segments. At the end of surgery, all rats were treated with the antibiotic ampicillin $(100 \mathrm{mg} / \mathrm{kg})$ and the analgesic ketorolac $(0.6 \mathrm{mg} / \mathrm{kg}$, s.c.). None of the injections produced obvious behavioral or motor deficits after $24 \mathrm{hr}$. All rats with spinal injections of FG were allowed to survive for $8 \mathrm{~d}$, and then they were anesthetized with urethane $(1.8 \mathrm{gm} / \mathrm{kg}$, i.p.) and perfused with formaldehyde as described above.

Preparation of digoxigenin-labeled $R N A$ probes for histological detection of VGLUT2 mRNA and PPE $m R N A$ by in situ hybridization. Both digoxigenin-labeled cRNA probes were prepared as described previously (Stornetta et al., 2001, 2002a). The antisense cRNA riboprobe for rat PPE was transcribed from a 1132 bp DNA template inserted into the EcoRI site of Bluescript SK + (Stratagene, La Jolla, CA) (Stornetta et al., 2001). The PPE construct was kindly supplied and previously characterized by R. Howells (University of Medicine and Dentistry of New Jersey-NJ Medical School) (Rao and Howells, 1992). The antisense cRNA riboprobe for rat VGLUT2 was transcribed from a 1119 bp DNA template inserted into the TOPO cloning site of pCRII-TOPO (Invitrogen, Carlsbad, CA) (Stornetta et al., 2002a). Both PPE and VGLUT2 antisense riboprobes were synthesized in an in vitro polymerization reaction using appropriate RNA polymerases (VGLUT2: SP6; PPE: T3; Promega, Madison, WI) in the presence of digoxigenin-11-UTP (Roche Molecular Biochemicals). The efficiency of digoxigenin-11-UTP incorporation was estimated by direct immunological detection on dot blots using a sheep polyclonal anti-digoxigenin antibody (Roche Molecular Biochemicals).

Histochemistry. All histochemical procedures were done using freefloating sections removed from the cryoprotectant mixture and rinsed three times in $1 \times$ Dulbecco's sterile PBS, pH 7.4. Hybridization histochemistry was performed as described previously (Stornetta et al., 2001, 2002a). Briefly, digoxigenin was revealed with a sheep polyclonal antidigoxigenin antibody conjugated to alkaline phosphatase (Roche Molecular Biochemicals), and alkaline phosphatase was reacted with nitroblue tetrazolium (NBT) and 5-bromo-4-chloro-3-indolyl-phosphate, 4-toluidine salt (BCIP). Previous testing has established the specificity of our probes (Stornetta et al., 2001, 2002a). Absence of labeling in facial, hypoglossal, and ambigual motor neurons was taken as quality standard because these cells are the most prone to exhibit nonspecific NBT/BCIP reaction product under suboptimal conditions. The in situ hybridization protocol was always performed before any immunohistochemistry, i.e., before detection of NK1R, biotinamide, or FG (Schreihofer and Guyenet, 1997; H. Wang et al., 2001). Briefly, NK1R immunoreactivity was detected using a guinea-pig polyclonal antibody (1:1000 dilution; Chemicon International, Temecula, CA), followed by a goat anti-guinea pig IgG conjugated to Cy3 (1:200 dilution; Jackson ImmunoResearch 
Laboratories, West Grove, PA). FG was detected using a rabbit polyclonal antibody (1:10,000 dilution; Chemicon) followed by anti-rabbit IgG conjugated to Alexa 488 (Molecular Probes). Biotinamide (juxtacellular labeling) was revealed with streptavidin Alexa 488 (1:200 dilution; Molecular Probes). The sections were mounted in sequential rostrocaudal order onto slides, dried, and covered with Vectashield (Vector, Burlingame, CA). No label was observed in the absence of any of the primary antibodies. In one experiment, NK1R immunoreactivity was detected using the NK1R antibody that was originally used to define the distribution of this receptor (Nakaya et al., 1994). This reagent was kindly provided by Dr. Ryuichi Shigemoto (National Institute for Physiological Sciences, Myodaiji, Okazaki, Japan). In this experiment the avidin-biotin method was used to detect NK1R immunoreactivity as described previously (H. Wang et al., 2001). The NK1R antibodies used in the present study, like those used by other investigators previously, are directed against the C-terminal end of the classic long form of the NK1 receptor (Nakaya et al., 1994; Brown et al., 1995; Gray et al., 1999). These antibodies should not be able to detect the alternatively spliced form of the NK1 receptor, which lacks the C terminus (Fong et al., 1992; Li et al., 1997).

Mapping and imaging. The sections were examined under dark-field illumination to identify the two sections that contained our chosen diagnostic landmarks. The first landmark was the very caudal end of the facial motor nucleus, which was assigned the level $11.6 \mathrm{~mm}$ caudal to bregma according to the atlas of Paxinos and Watson (1998). The second landmark was the rostral end of the lateral reticular nucleus, where this structure displays a lateral and a medial portion as opposed to a single outline. The section corresponding to that landmark was assigned the level $13.0 \mathrm{~mm}$ caudal to bregma according to the nomenclature of Paxinos and Watson (1998). The theoretical distance between the two landmark sections $(1.4 \mathrm{~mm})$ closely matched the actual distance represented by the product of the number of intervening sections times the section thickness $(30 \mu \mathrm{m})$. Therefore the bregma level of the intervening sections was determined arithmetically by their location relative to the two landmark sections.

The outlines and major landmarks of the sections of interest were drawn under dark-field illumination using a motor-driven microscope stage controlled by the Neurolucida software as described previously (Stornetta and Guyenet, 1999). This system was also used to map the location of the neurons of interest using a $40 \times$ or $25 \times$ objective and to draw the outline of cell somata under a $100 \times$ objective. The Neurolucida files were exported to the NeuroExplorer software (MicroBrightfield, Colchester, VT) to count the various types of neurons within a defined area of the reticular formation or to obtain measurements of soma size, including circumference, area, and ferets. The Neurolucida files were exported to the Canvas6 software drawing program for final modifications. Photographs were taken with a 12-bit color CCD camera (CoolSnap, Roper Scientific, Tucson, AZ; resolution $1392 \times 1042$ pixels) (Stornetta et al., 2002a). The neuroanatomical nomenclature is after Paxinos and Watson (1998).

Statistics. The average linkage method of cluster analysis (SAS v. 8.2; procedure: cluster) was applied to the coordinate data of Figure 7 (spikes per burst vs conduction velocity). Before the technique was applied, the variables were first standardized to variables with mean 0 and SD 1 . The cubic clustering criterion and the pseudo F statistic identified two clusters as the optimal number of clusters. Other methods of cluster analysis were also applied and yielded the same results. Group data are expressed as means \pm SEM and were compared by $t$ test.

\section{RESULTS}

\section{VGLUT2 mRNA is present in most of the NK1R-ir neurons of the ventral respiratory group}

To test whether NK1R-ir neurons of the VRG are glutamatergic, we determined whether these neurons express the mRNA encoding the vesicular glutamate transporter VGLUT2, the predominant vesicular transporter subtype found in the brainstem. To also test whether some of these cells project to the spinal cord, these experiments were performed in three rats that had received an iontophoretic injection of FG into the ventral horn of spinal segment C4. The resulting injection sites were spherical, confined to the left ventral horn with variable encroachment on lamina 6 , and spared the white matter. The ensuing pattern of retrograde labeling in the VRG was used to pinpoint the location of the $\mathrm{rVRG/pre-BötC}$ transition because this level is characterized by an abrupt reduction in the density of bulbospinal neurons with projections to the phrenic motor nucleus (Ellenberger and Feldman, 1990; Dobbins and Feldman, 1994; Feldman and McCrimmon, 1999).

The histological appearance of neurons containing VGLUT2 mRNA is shown in Figure $1 A-D, F$. Examples of neurons that contained both VGLUT2 mRNA and NK1R immunoreactivity are also shown in Figure $1 E, F$. VGLUT2 mRNA was absent from fiber tracts (e.g., pyramidal tract) (Fig. $1 A$ ) and from cholinergic neurons that were assumed not to use glutamate as transmitter, such as hypoglossal (Fig. $1 B$ ) or ambigual motor neurons (Fig. $1 C)$. VGLUT2 mRNA was found in vast numbers of inferior olivary neurons as expected (Fremeau et al., 2001; Stornetta et al., 2002a) (Fig. 1A). Neurons expressing VGLUT2 were abundant in the VRG at the level of the pre-BötC (Fig. 1C). The rVRG, identified by the large number of cells retrogradely labeled from the $\mathrm{C} 4$ ventral horn, also contained many VGLUT2-positive neurons (Fig. 1D).

Five classes of cells could be distinguished on the basis of the presence of one or more of the three markers (VGLUT2, FG, NK1R). Computer-assisted mapping of these cells was done at six medullary levels $(11.7,12.06,12.42,12.78,13.16$, and $13.52 \mathrm{~mm}$ behind bregma). Mapping was done only in the ventrolateral medulla on the side ipsilateral to the spinal injection, although the number of bulbospinal projections from the VRG appeared similar on both sides. This symmetry was expected because most VRG inspiratory premotor neurons have bilateral projections in the rat (Duffin et al., 2000). Cells were counted within a $750 \times$ $500 \mu \mathrm{m}$ box delineating the VRG (Fig. 2). The box was positioned so that the middle of its upper side coincided with the bottom of the compact portion of nucleus ambiguus. This nucleus is easily identifiable rostrally (bregma -11.7 to $-12.7 \mathrm{~mm}$ ) in tissue stained for NK1R because of its very high level of immunoreactivity. Caudal to this level the nucleus ambiguus is ill-defined, and the counting box was centered in the VRG around a well defined, roughly circular cluster of FG-labeled neurons presumed to consist primarily of inspiratory premotor neurons (Fig. 2) (bregma level $-13.0 \mathrm{~mm})$.

The example shown in Figure 2 illustrates that at the level of the pre-BötC (12.42 mm behind bregma), the vast majority of the NK1R-ir neurons contained VGLUT2 mRNA (filled triangles). At more caudal levels (12.78 and $13.0 \mathrm{~mm}$ behind bregma), this was still the case, but, in addition, a fraction of the NK1R-ir neurons also projected to C4 (stars). Large NK1R-ir neurons devoid of VGLUT2 mRNA were frequently encountered outside the VRG along the ventral surface of the medulla (Fig. 2, all levels). These neurons may be GABAergic (H. Wang et al., 2001). Smaller NK1R-ir neurons devoid of VGLUT2 mRNA were found more frequently in the Bötzinger region (Fig. 2) (bregma $-12.06 \mathrm{~mm}$ ). At this very rostral level, a few of these cells may be cholinergic neurons (H. Wang et al., 2001).

The average cell counts from three rats are shown in Figure 3. Figure $3 A$ represents the rostrocaudal distribution of bulbospinal neurons within the VRG on the side ipsilateral to the spinal injection. The largest concentration of bulbospinal cells was found caudal to bregma $-12.7 \mathrm{~mm}$, identifying this level as the rostral tip of the rVRG. Within the rVRG, $>90 \%$ of the bulbospinal neurons contained VGLUT2 mRNA (Fig. 3A), consistent with the known presence of large numbers of bulbospinal inspiratory glutamatergic premotor neurons at this level (Dong 

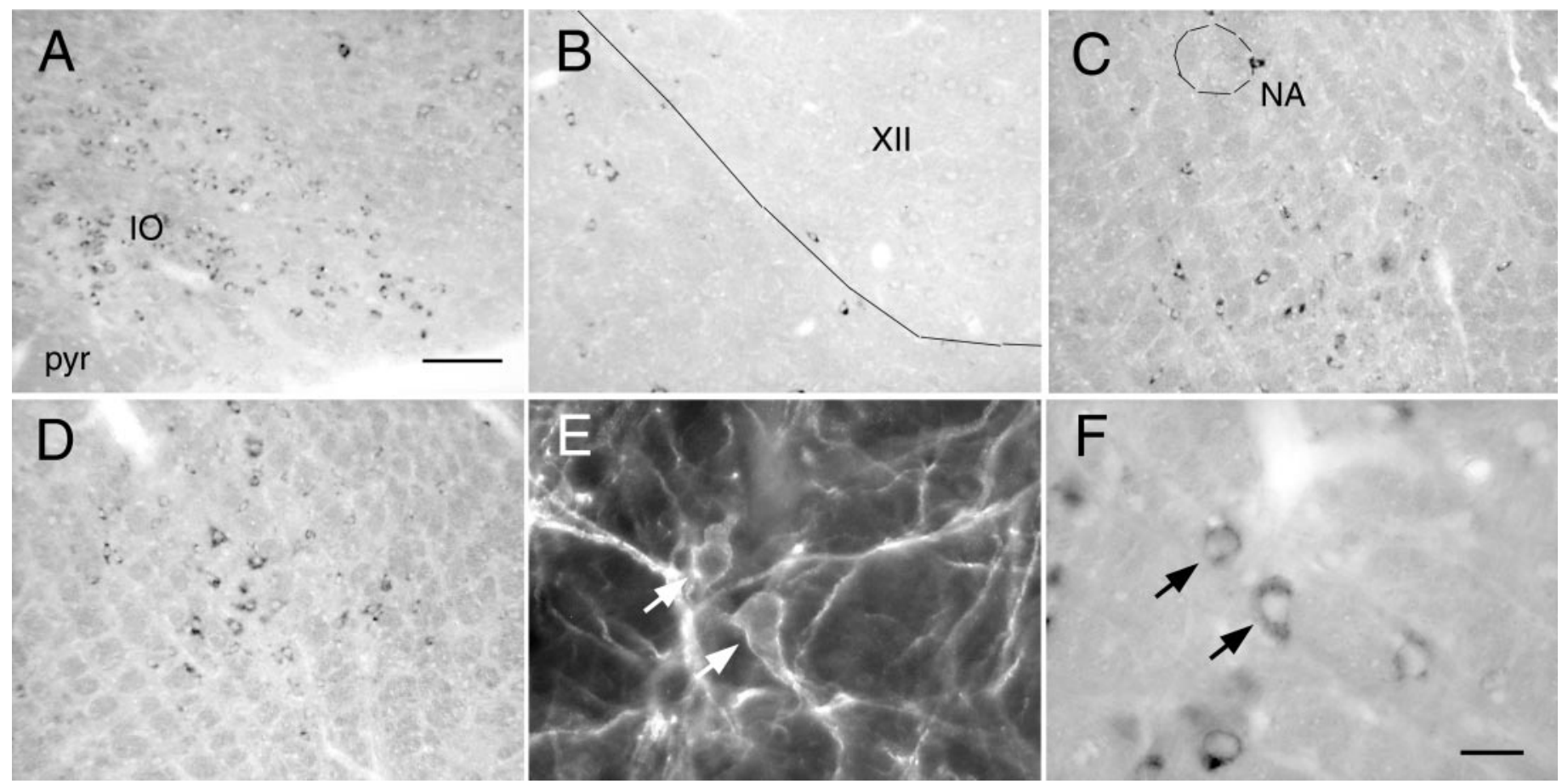

Figure 1. VGLUT2 mRNA in the NK1R-ir neurons of the VRG. $A$, VGLUT2 mRNA is present in the inferior olive (IO) but absent from the pyramidal tract ( pyr). B, VGLUT2 mRNA is absent from the hypoglossal motor nucleus (XII). C, VGLUT2 mRNA is present in the pre-BötC (bregma - $12.4 \mathrm{~mm}$ ) but absent from nucleus ambiguus $(N A)$. $D$, VGLUT2 mRNA is present in the rVRG (bregma $-13.0 \mathrm{~mm}$ ). NK1R-ir neurons shown under fluorescence illumination in $E$ contain VGLUT2 mRNA as seen under bright-field in $F$ (arrows show two double-labeled neurons). Scale bars (shown in $A$ ): $A-D$, 100 $\mu \mathrm{m}$; (shown in $F$ ): $E, F, 20 \mu \mathrm{m}$.

and Feldman, 1995; Dong et al., 1996). The rostral half of the rVRG contained bulbospinal neurons that expressed both VGLUT2 mRNA and NK1R immunoreactivity (Fig. 3A). Strikingly, $100 \%$ of the NK1R-ir neurons identified as bulbospinal also contained VGLUT2 mRNA.

Figure $3 B$ shows that a large majority of the NK1R-ir neurons (bulbospinal plus others) expressed detectable levels of VGLUT2 mRNA. The proportion varied from $67 \%$ at the rostral end of the VRG (Bötzinger region) to $100 \%$ at the caudal end (rVRG). The average for the entire VRG (all five levels pooled) was $76.6 \%$, although this figure varied between animals (60, 80, and 89.8\%). This intersubject variability probably reflects differences in the detection of the VGLUT2 mRNA NBT/BCIP reaction product, and thus the highest figure $(89.8 \%)$ may be closest to the truth (see Discussion for methodological considerations).

\section{PPE mRNA defines two classes of VRG NK1R-ir neurons}

PPE mRNA is expressed by many neurons within the cardiorespiratory region of the rostral ventrolateral medulla (Stornetta et al., 2001b). The following experiments performed in six rats were designed to determine whether PPE mRNA is expressed by some of the NK1R-ir neurons of the VRG. Two animals received large bilateral FG injections in cervical segment $\mathrm{C} 4$, and two others received similarly large bilateral injections into spinal thoracic segment T3. The ensuing pattern of retrograde labeling in the VRG was used to identify the location of the rVRG/pre-BötC transition (see above). The larger pressure injections were designed to maximize the number of retrogradely labeled bulbospinal neurons in the VRG. We also used tissue from two of the three rats that had received small iontophoretic injections of FG into the phrenic motor nucleus. A one in six series of sections (180 $\mu \mathrm{m}$ apart) from each of the six rats was processed for the simultaneous detection of PPE mRNA, NK1R-ir, and FG immunoreactivity. Mapping was done only in the ventrolateral medulla on the left side of the brain.

The presence or absence of PPE mRNA defined two classes of VRG NK1R-ir neurons with differing somatic sizes but equally intense immunoreactivity (Fig. 4). The NK1R-ir neurons devoid of PPE mRNA had small fusiform cell bodies from which one or usually two primary dendrites emerged in the coronal plane (Fig. $4 A, C)$. The NK1R-ir neurons that expressed PPE mRNA were larger and generally multipolar (Fig. 4B,E,F). The difference in size and cell body morphology between these neurons is further illustrated by high-magnification confocal photomicrographs in Figure 4, $A$ and $B$. Computer-aided measurements of somatic size (perimeter, cross-sectional area, largest width, and length) were made in neurons of each class selected at random in the VRG between bregma -12.2 and $-12.9 \mathrm{~mm}$. These measurements revealed a striking 2.5-fold difference in average cross-sectional area between the PPE mRNA expressing NK1R-ir cells and the rest of the NK1R-ir cells, with very little overlap between the two populations (Table 1). The absence of PPE mRNA signal in the small NK1R-ir neurons of the VRG was not caused by a lack of sensitivity of the hybridization method, because equally small or smaller neurons within the nucleus of the solitary tract routinely expressed high levels of PPE mRNA reaction product (result not illustrated).

The rostrocaudal distribution of the two classes of NK1R-ir neurons (with and without PPE mRNA) was also different (Fig. 5). This figure describes the location of five classes of neurons defined by the presence or absence of the three histological markers (NK1R, FG, PPE mRNA) within the $750 \times 500 \mu \mathrm{m}$ box 


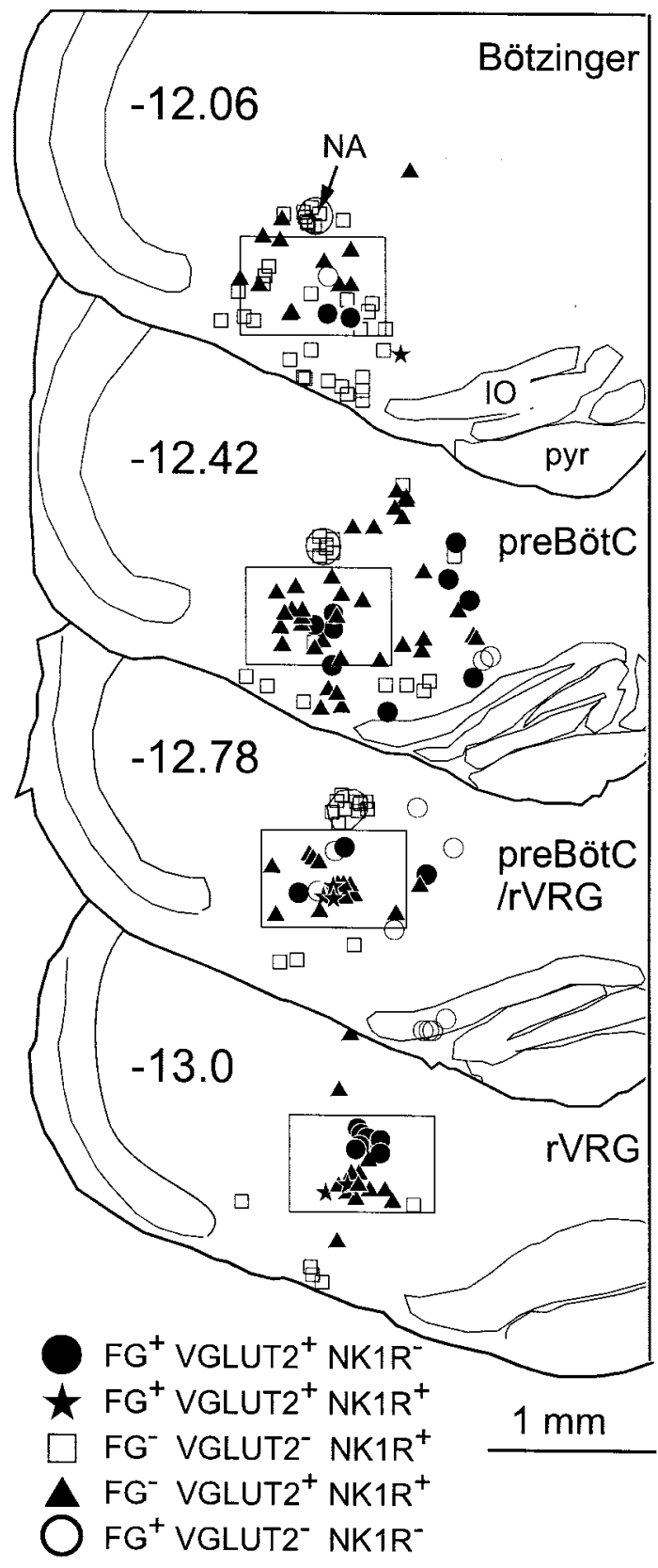

Figure 2. Rostrocaudal distribution of five cell types at four levels of the VRG. Five categories of cells are shown in four sections from a single representative brain. Neurons that contained only VGLUT2 mRNA are not represented. The $750 \times 500 \mu \mathrm{m}$ box outlines the region of the medulla where cell counts were made. Numbers on each section refer to location relative to bregma (in millimeters). $F G$, Cells immunoreactive for FluoroGold retrogradely transported from spinal cord $\mathrm{C} 4 ; N A$, nucleus ambiguus pars compacta; $I O$, inferior olive; pyr, pyramidal tract.

defined in Figure 2. On the basis of the pattern of retrograde labeling from the cord, the $\mathrm{rVRG}$ /pre-BötC transition point was found again at Bregma $-12.7 \mathrm{~mm}$ (Fig. $6 \mathrm{~A}$ ). The same transition point was identified regardless of whether FG was injected in C5 or T3 or by pressure injection or iontophoresis. The distribution of bulbospinal neurons shown in Figure $5 A$ is therefore an average of the six animals. In agreement with our previous results, NK1R-ir neurons were broadly distributed within the VRG, with a peak located just rostral to rVRG (Fig. $5 A$ ). The small NK1R-ir neurons devoid of PPE mRNA were concentrated around bregma $-12.3 \mathrm{~mm}$, and their number decreased abruptly in the rVRG (caudal to bregma $-12.7 \mathrm{~mm}$ ), a structure identified by its large number of bulbospinal neurons (Fig. $5 B$ ). Thus the bulk of the small fusiform NK1R-ir neurons is located in the pre-BötC, although cells with apparently similar characteristics are also present in the Bötzinger region. A very rough estimate of the number of fusiform NK1R-ir and PPE-negative cells present per side in the area defined at pre-BötC (Fig. 2, box) over a rostrocaudal span of $500 \mu \mathrm{m}$ (bregma -12.1-12.6 mm) is 220 (16.6 sections with an average of 13 cells per section), but it should be emphasized that the present method was not designed to produce accurate counts of the total number of cells present in a given three-dimensional area. The larger NK1R-ir neurons that express high levels of PPE message had a broad distribution with a peak at the rostral end of the rVRG (Fig. 5B). As expected, we found that some of the intensely fluorescent NK1R-ir neurons of the VRG contained FG, indicating that these cells have spinal projections. Bulbospinal NK1R-ir cells were detected in all six rats, although their number was higher in the four animals that had received larger pressure injections of FG (C4 or T3) than in the two rats that had received iontophoretic injections of FG at $\mathrm{C} 4$. Without exception, all of the FG-labeled NK1R-ir neurons of the VRG were of the large multipolar type, and they contained PPE mRNA. The rostrocaudal distribution of these cells was the same in the rats that had received pressure injections into the cervical cord as in those with thoracic level injections. The pooled results from these four rats are shown in Figure $5 B$. This figure indicates that all bulbospinal NK1R-ir neurons were located in the rostral half of the rVRG. At this level, these cells constituted $<20 \%$ of all the retrogradely labeled $\mathrm{rVRG}$ neurons.

In one experiment, NK1R immunoreactivity was detected using the NK1R antibody that was used to provide the original map of CNS NK1 receptors (Nakaya et al., 1994). The pattern of NK1R staining in the VRG could not be distinguished from that obtained with the commercial antibody, and the selective association between large NK1R-ir neurons and PPE mRNA was verified (results not shown).

\section{Bulbospinal NK1R-ir neurons of the rVRG include a subtype of the inspiratory-augmenting neuron}

It has been hypothesized that NK1R immunoreactivity might be a diagnostic marker for a group of respiratory rhythmogenic interneurons of the VRG (Gray et al., 1999). However, the existence of NK1R-ir with spinal projections and the location of these cells (rostral part of the rVRG) suggested to us that NK1 receptors may also be expressed by inspiratory bulbospinal premotor neurons (Duffin et al., 1995). The next experiments were designed to test whether the bulbospinal NK1R-ir neurons of the rVRG could indeed be inspiratory premotor neurons and whether all or only a fraction of the inspiratory premotor neurons express this receptor. To do so we recorded from $\mathrm{rVRG}$ bulbospinal inspiratory-augmenting (I-AUG) neurons, and we labeled them juxtacellularly with biotinamide. The tissue was processed for detection of NK1R immunoreactivity to determine whether the recorded cells expressed NK1 receptors.

In nine rats, the VRG was explored between 1.1 and $1.6 \mathrm{~mm}$ caudal to the caudal end of the facial motor nucleus because this region (bregma -12.8 to $-13.3 \mathrm{~mm}$ ) contains the highest density of cells with projections to the phrenic motor nucleus (Fig. 3). In contrast to the rostrally located pre-BötC $(0.6-1.0 \mathrm{~mm}$ behind facial motor nucleus), this region of the VRG contained large 

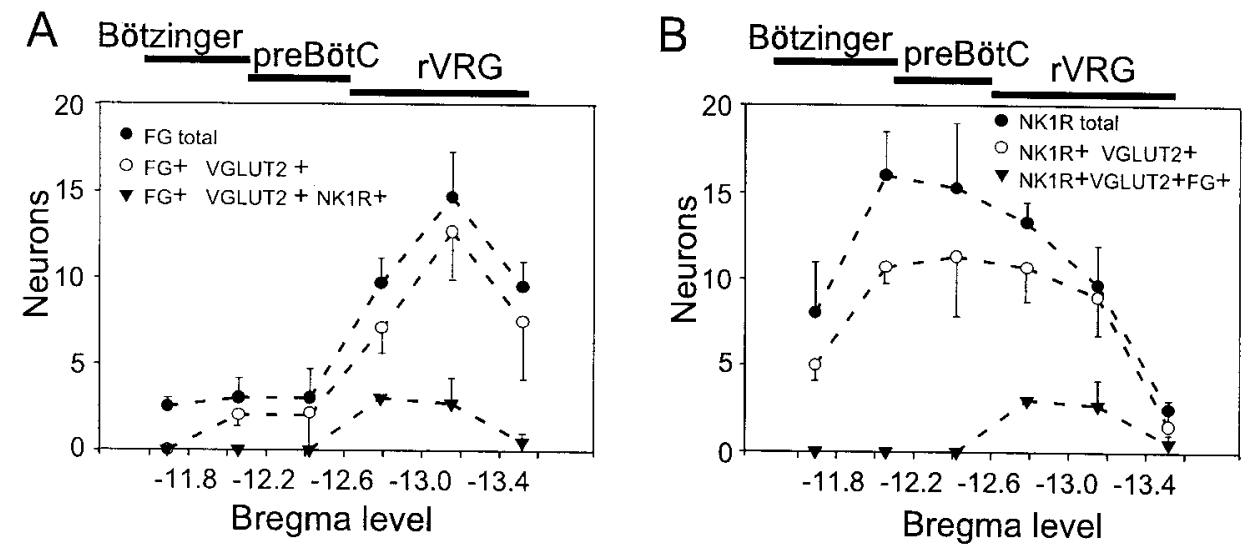

Figure 3. Most NK1R-ir neurons of the VRG contain VGLUT2 mRNA. $A$, Rostrocaudal distribution of bulbospinal neurons within the $750 \times 500 \mu \mathrm{m}$ box defined in Figure 2. Spinally projecting $\left(F G^{+}\right)$NK1R-ir neurons were concentrated at the rostral end of the rVRG. $B$, Rostrocaudal distribution of NK1R-ir neurons. The vast majority of NK1R-ir neurons, including $100 \%$ of the bulbospinal ones, contained VGLUT2 mRNA. Ordinate indicates mean \pm SE number of neurons counted per section on the side ipsilateral to the $\mathrm{FG}$ injection ( $n=3$ rats). FG was iontophoretically injected into the ventral horn at $\mathrm{C} 4$. The bars above the graphs indicate our best estimate of the minimum probable rostrocaudal extent of the Bötzinger, pre-BötC, and rVRG based on this study and previous electrophysiological work (Guyenet and Wang; 2001; H. Wang et al., 2001). numbers of inspiratory neurons with incrementing discharge (IAUG). These cells could be divided into two types. The most commonly found I-AUG neurons discharged at a very high rate during inspiration. Their discharge onset corresponded closely to that of the phrenic nerve (Fig. 6A1), and they exhibited an incremental rate of discharge that could reach $>200$ spikes per second (Fig. 6A1, $205 \mathrm{~Hz}$ ). This high discharge rate typically caused a slight decrement in spike height at the end of the burst (Fig. 6A1). In virtually every case, spikes with constant and very short latency could be observed in these fast-discharging I-AUG cells after spinal cord stimulation (Fig. 6A2, $1.2 \mathrm{msec}$ ). The collision test (Lipski, 1981) illustrated in Figure $6 A 2$ was used to demonstrate that these constant latency spikes were antidromic. The constant latency action potentials $(a)$ evoked by spinal cord stimulation (arrow) were not evoked (sweeps denoted by an asterisk) when the stimulus was delivered within a critical interval (1.1 msec in this example) after a spontaneously occurring spike $(s)$. The discharge of the cells was eliminated by hyperventilation, and it maintained the same temporal relationship to the PND when ventilation was interrupted, indicating that the discharge of the cell did not require lung afferent input (data not shown).

A second class of I-AUG cells was also encountered (Fig. 6B1). At rest, these neurons had a much lower rate of discharge and thus much smaller numbers of spikes per phrenic burst (from $<1$ to 20). An extreme case is shown in Figure $6 \mathrm{B1}$. The discharge rate of the slow I-AUG cells was increased along with the inspiratory drive (PND amplitude), when ventilation was interrupted for brief periods $(10-20 \mathrm{sec})$. During these episodes the cells remained phase-locked with the PND (Fig. 6B2), but they fired earlier and earlier during the phrenic burst. This firing pattern suggests that they are indeed high-threshold I-AUGs and not late inspiratory cells. These cells could also be antidromically activated from $\mathrm{C} 5$ but their antidromic latency was typically much longer than that of the fast-conducting neurons $(5-55 \mathrm{msec}$; a typical example is shown in Fig. 6B3).

Figure 7 illustrates the relationship between discharge rate (spikes per phrenic burst) and conduction velocity (two-point determination based on an estimated straight-line distance of 25 $\mathrm{mm})$ for all the I-AUG cells analyzed $(n=49)$. The cubic clustering criterion and the pseudo $\mathrm{F}$ statistic identified two clusters as the optimal number (see Materials and Methods). Thus, I-AUG neurons may belong to two groups: one with low discharge rate and slow conduction velocity (high-threshold I-AUG cells, $n=21$; cluster 1 ) and the other with high discharge rate and fast conduction velocity (low-threshold I-AUG cells, $n=$ 28; cluster 2). The distance from the origin was calculated for each data point. The distribution of distance measures for cluster 1 did not overlap with that for cluster 2 ; hence this numerical

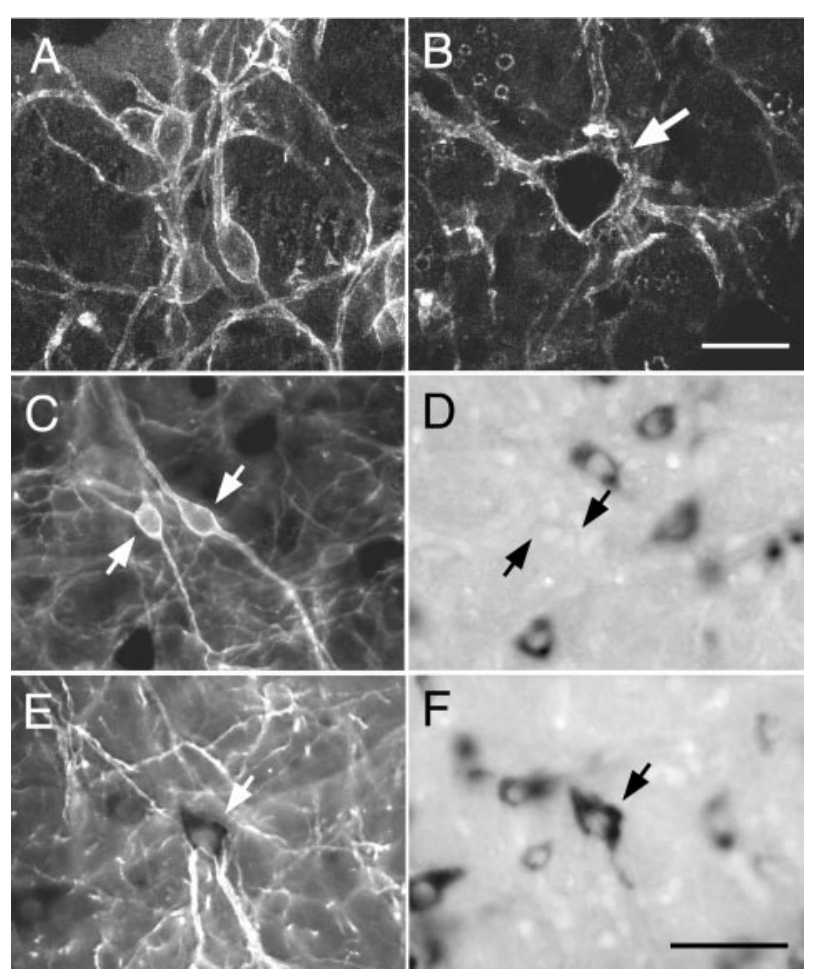

Figure 4. Cell size and presence of PPE mRNA define two types of NK1R-ir neurons in the VRG. $A, B$, Confocal images of a cluster of small NK1R-ir neurons within the pre-BötC $(A)$ and of a large isolated NK1R-ir neuron of the rVRG (B, arrow). The inside of the cell shown in $B$ is especially dark because Cy3 fluorescence is quenched by dense VGLUT2 mRNA reaction product. $C, D$, Light microscopic images of a cluster of small neurons of the pre-BötC under fluorescence $(C)$ and bright-field illumination $(D)$. The NK1R-ir cells $(C$, arrows) are devoid of PPE mRNA $(D)$ but are surrounded by neurons lacking NK1R immunoreactivity that express high levels of PPE mRNA. $E, F$, Light microscopic images of a large NK1R-ir neuron of the rVRG under fluorescence $(E)$ and bright-field illumination $(F)$. The dendrites of this cell display intense NK1R immunofluorescence $(E)$, whereas in the cell body, NK1R immunofluorescence is quenched by the very high level of PPE mRNA reaction product $(F)$. Scale bars (shown in $B$ ): $A, B, 20 \mu \mathrm{m}$; (shown in $F$ ): $C-F, 50 \mu \mathrm{m}$. 


\begin{tabular}{lllll}
\hline Table 1. Cross-sectional area of NK1R-ir neurons with or without PPE mRNA & & \\
Type of NK1R-ir cell & $\begin{array}{l}\text { Perimeter }(\mu \mathrm{m}) \\
(\mathrm{M} \pm \mathrm{SE} \text {; range })\end{array}$ & $\begin{array}{l}\text { Surface }\left(\mu \mathrm{m}^{2}\right) \\
(\mathrm{M} \pm \mathrm{SE} \text {; range })\end{array}$ & $\begin{array}{l}\text { Feret maximum }(\mu \mathrm{m}) \\
(\mathrm{M} \pm \mathrm{SE} \text {; range })\end{array}$ & $\begin{array}{l}\text { Feret minimum }(\mu \mathrm{m}) \\
(\mathrm{M} \pm \mathrm{SE} \text {; range })\end{array}$ \\
\hline Without PPE mRNA $(n=31)$ & $29.5 \pm 1.5$ & $90.9 \pm 3.6$ & $15.3 \pm 0.6$ & $8.7 \pm 0.2$ \\
& $(30.3-76.5)$ & $(57.4-133)$ & $(11-26.6)$ & $(6.9-11.3)$ \\
With PPE mRNA $(n=26)$ & $70.2 \pm 2.7^{*}$ & $252 \pm 15^{*}$ & $26.8 \pm 1.1^{*}$ & $14.9 \pm 0.6^{*}$ \\
& $(42.5-97.2)$ & $(102-393)$ & $(16.3-36.6)$ & $(9.3-21)$
\end{tabular}

${ }^{*} p<0.0001(t$ test $)$.

Figure 5. Distribution of NK1R-ir neurons that contain PPE mRNA. The plots represent the number of neurons (mean $\pm \mathrm{SE}$ ) per hemisection found within the $750 \times 500 \mu \mathrm{m}$ box outlined in Figure 2 ( $n=6$ rats). $A$, Rostrocaudal distribution of all NK1R-ir neurons and all bulbospinal neurons. The dip in the curve representing the bulbospinal neurons $\left(\mathrm{FG}^{+}\right.$total $)$identifies the location of the pre-BötC. $B$, Distribution of three classes of VRG NK1R-ir neurons based on the presence or absence of PPE mRNA and spinal projections to $\mathrm{C} 4$ or T3. All of the bulbospinal NK1R-ir neurons contained PPE mRNA.
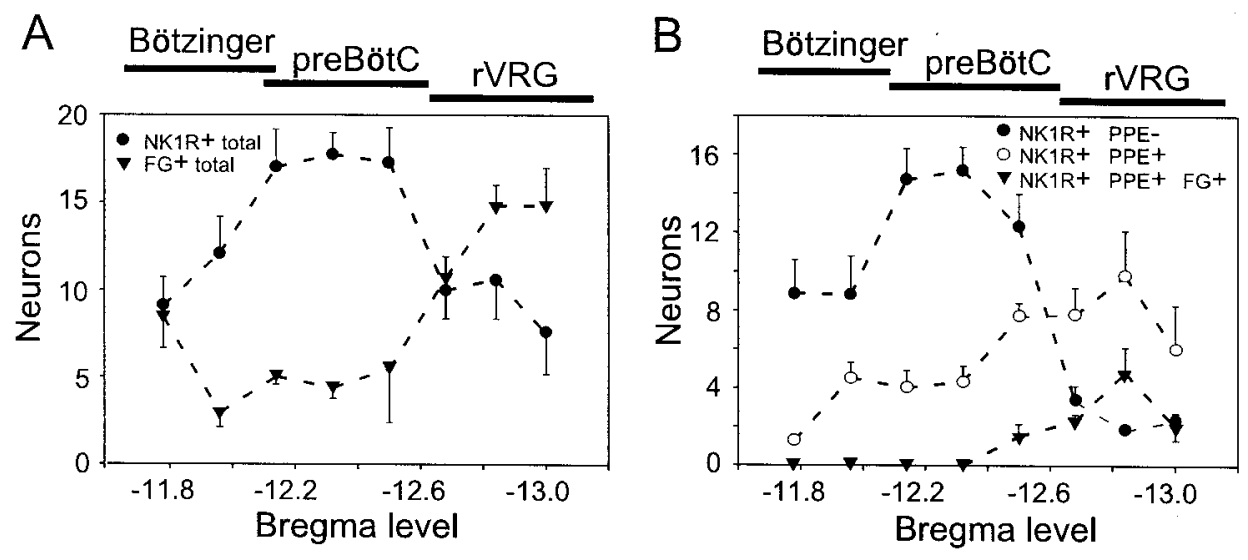

Figure 6. Low- and high-threshold inspiratory augmenting neurons of the rVRG: characterization and labeling. $A 1-A 3$, Low-threshold unit; $B 1-B 3$, high-threshold unit. $A 1$, Resting discharge of a typical low-threshold neuron. Note the incrementing discharge of the cell (fourth trace from top: rate; fifth trace from top: original unit recording), which resembles the discharge pattern of the phrenic nerve ( $i P N D$, integrated discharge; $P N D$, original nerve discharge). A2, Collision test demonstrating that the cell has an axonal projection to spinal level C4 ( $s$, spontaneous spike; arrowhead, stimulus artifact; $a$, antidromic spike; asterisks indicate sweeps when collisions occurred). Antidromic latency of this unit was $1.2 \mathrm{msec} . A 3$, Juxtacellular labeling by entrainment of the cell discharge with intermittent pulses of depolarizing current. B1, Resting discharge of high-threshold neuron. $B 2$, Same unit during brief interruption of ventilation. B3, Collision test. The antidromic latency of this unit was 17.9 msec.
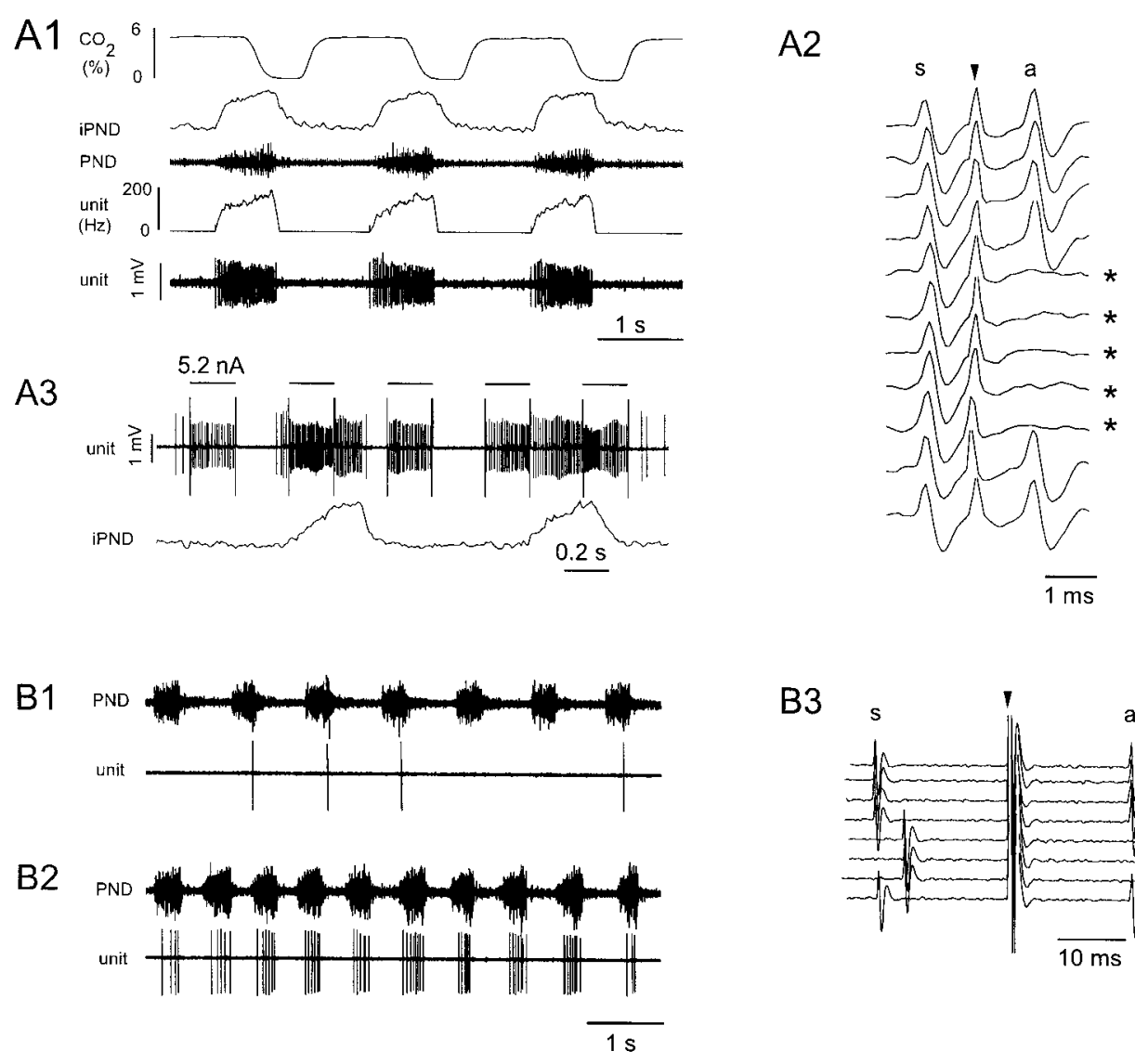

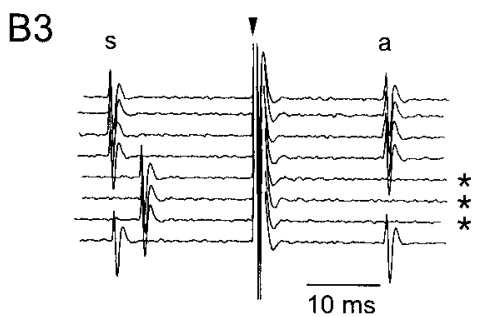

value may have diagnostic value. The two clusters were also well differentiated by the number of spikes per burst $(9.6 \pm 1.5$ vs $51.5 \pm 2.5 ; p<0.001)$ and conduction velocity $(4.5 \pm 0.7$ vs 16.4 vs $0.9 ; p<0.001)$, with only minor overlap. A sparse section in the center of each of the distributions for distance, spikes per burst, and conduction velocity (meters per second) reinforced the impression of two populations of data.

The end-expiratory $\mathrm{CO}_{2}$ was $5.85 \pm 0.1 \%$ for the 29 neurons 


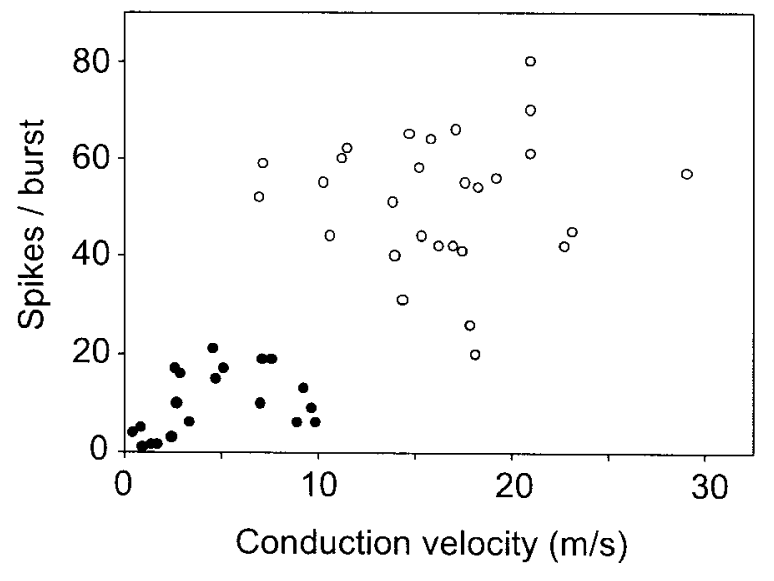

Figure 7. Relationship between discharge rate and axonal conduction velocity of inspiratory augmenting neurons. Mean number of spikes per burst under resting condition (averaged over 20 consecutive bursts) plotted against the conduction velocity of the spinal axon $(25 \mathrm{~mm}$ estimated straight-line distance between stimulating and recording points divided by antidromic latency). $n=49$ cells. The two cell clusters delineated by the average linkage method (see Materials and Methods) are identified by (high-threshold cells) and $\bigcirc$ (low-threshold neurons).

firing above 20 spikes per respiratory burst and $6.23 \pm 0.16 \%$ for the 20 I-AUG cells with $0-20$ spikes per burst. Thus the slower discharge rate of the slow-conducting neurons was clearly not caused by a difference in the $\mathrm{CO}_{2}$ level and, presumably, in central inspiratory drive. In fact, because many of these cells were discharging so slowly, ventilation was deliberately reduced to permit their characterization, which accounts for the slightly higher baseline $\mathrm{CO}_{2}$ level registered during analysis of their discharge rate. Both types of neurons (slow and fast discharging) could be reliably entrained by the extracellular pulses of positive current (2.5-8 nA; $5.2 \mathrm{nA}$ in Fig. $6 \mathrm{A3}$ ) procedure, which resulted in their labeling with biotinamide. Note that during the entrainment, the cell maintained its normal respiratory pattern of discharge, but the stimulus was strong enough to activate the cell during the normally silent expiratory phase.

Most of the I-AUG cells labeled with biotinamide were not NK1R-ir (38 of 42). This general case is illustrated in Figure $8 A, B$. Note that the biotinamide-labeled cell lies in immediate proximity to another neuron that did express very high levels of NK1R immunoreactivity. In the first six rats in which only fastfiring I-AUG cells were labeled, we did not find a single NK1R-ir cell (of 28). The location of these 28 neurons is shown in Figure $9 A$. In the three remaining rats, we labeled preferentially I-AUG cells with slow axonal conduction velocity (11 neurons of 14 with an antidromic latency of $>5 \mathrm{msec}$ ). Four of the labeled cells were NK1R-ir (Fig. $8 C, D$ ), suggesting that NK1R-ir cells may be a subtype of the high-threshold I-AUG cells. The location of the 14 predominantly slow I-AUG cells recovered in these last experiments is shown in Figure $9 B$. The anatomical distribution of the low- and high-threshold bulbospinal I-AUG neurons was similar (Fig. 9, compare $A, B$ ), although the NK1R-ir neurons appear to lie at the lower edge of the column of I-AUG neurons (Fig. 9B).

\section{DISCUSSION}

According to this study, the NK1R-expressing neurons of the VRG are functionally heterogeneous but predominantly glutamatergic. A group of small fusiform neurons that lack PPE mRNA is primarily restricted to the pre-BötC and may be the
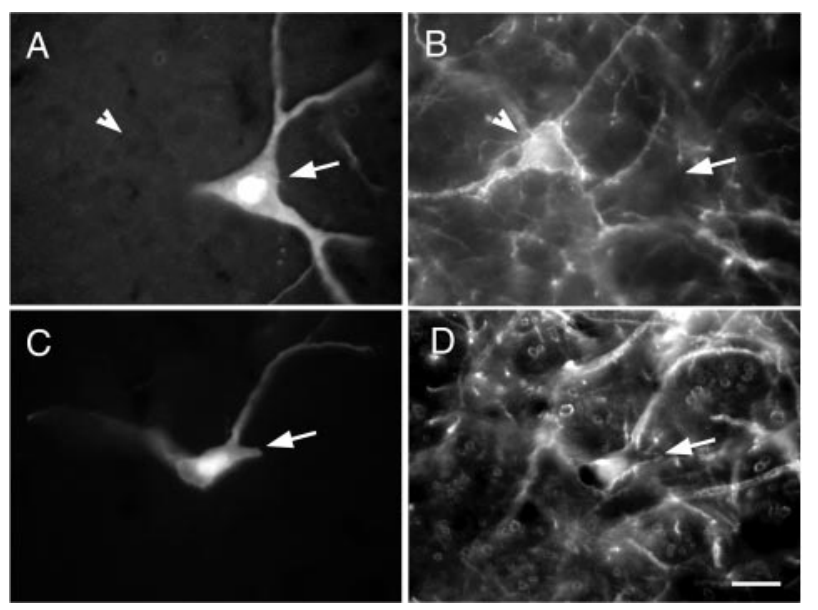

Figure 8. Examples of inspiratory augmenting neurons labeled with biotinamide. $A, B$, Biotinamide-filled I-AUG neuron $(A$, arrow) with fast discharge rate and fast axonal conduction velocity that lacks NK1Rimmunoreactivity $(B$, arrow). Note presence of NK1R immunoreactivity in an adjacent cell $(B$, arrowhead). $C, D$, Biotinamide-labeled I-AUG neuron $(C)$ with low discharge rate and slow axonal conduction velocity that contained NK1R-immunoreactivity $(D)$. Scale bar, $25 \mu \mathrm{m}$.

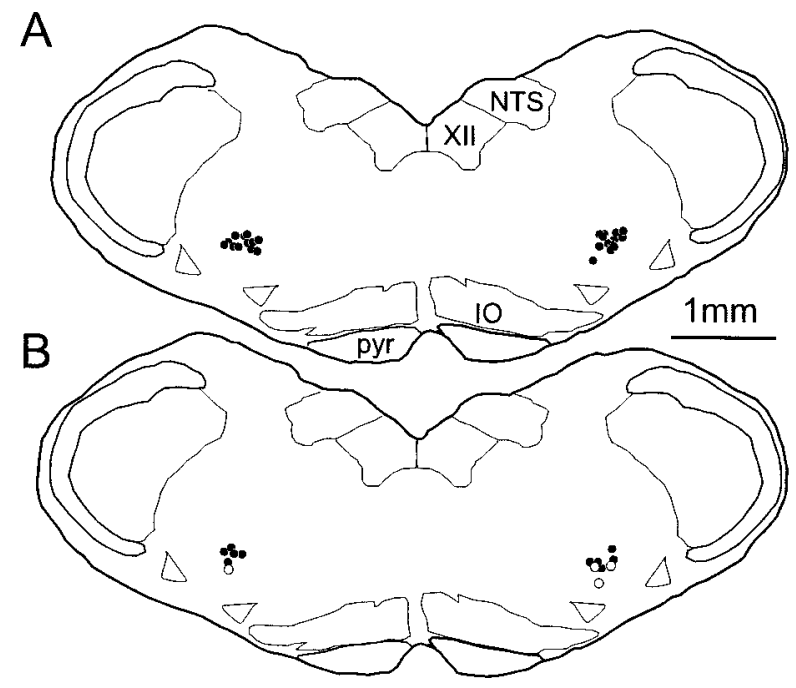

Figure 9. Location and phenotype of labeled inspiratory augmenting neurons. $A$, Location of 28 biotinamide-labeled I-AUG neurons with fast discharge rate and fast axonal conduction velocity (low-threshold cells) recorded in six rats. $B$, Location of 14 biotinamide-labeled I-AUG, predominantly high-threshold (11 of 14$)$ neurons recorded in three rats.

-, Neurons without NK1R immunoreactivity. O, NK1R-ir neurons. All cells were plotted on the same coronal plane (bregma $-13.0 \mathrm{~mm}$ ). NTS, Nucleus of the solitary tract; $I O$, inferior olive; pyr, pyramidal tract; XII, hypoglossal nucleus.

interneurons the destruction of which produces massive disruptions of the respiratory rhythm (Gray et al., 2001). The remaining VRG NK1R-ir neurons, including the bulbospinal ones of the rVRG, are larger multipolar cells that express PPE mRNA and include premotor neurons.

\section{Technical considerations}

The recent identification of two rat vesicular glutamate transporters, VGLUT1 and VGLUT2, now provides diagnostic tools to identify glutamatergic neurons (Takamori et al., 2000; Bai et al., 2001; Fremeau et al., 2001). Only VGLUT2 is expressed in the 
VRG (Stornetta et al., 2002a). Under our experimental conditions, VGLUT2 is absent from GABAergic or cholinergic neurons (Stornetta et al., 2002a), but it is present in known glutamatergic cells such as the inferior olive (Auger and Atwell, 2000; Ito, 2001) or the bulbospinal neurons of the rVRG (Dong et al., 1996; Feldman and McCrimmon, 1999). Thus our histological method appears to correctly identify glutamatergic neurons; however, the VGLUT2 mRNA reaction product was light, and some of the cells that express this transporter may not have been identified. In contrast, the PPE cRNA probe produced an extremely dense reaction product (Fig. 4), suggesting that absence of labeling was truly indicative of very low mRNA levels.

\section{Most NK1R-ir neurons of the VRG are glutamatergic}

The presence of VGLUT2 mRNA in $77 \pm 9 \%$ of VRG NK1R-ir cells demonstrates that most of these neurons are glutamatergic and confirms a previous tentative phenotyping based on glutamate immunoreactivity (Liu and Wong-Riley, 2001). In agreement, GAD67 mRNA is rarely detectable in VRG NK1R-ir cells $(<10 \%)$, and they are not glycinergic, cholinergic, or catecholaminergic (Gray et al., 1999; H. Wang et al., 2001). Because the hybridization method may not be sensitive enough to detect all of the cells that contain VGLUT2 mRNA, we may have underestimated the proportion of VRG NK1R-ir cells that are glutamatergic. However, we also cannot exclude the possibility that that up to $23 \%$ of the NK1R-ir cells of the VRG might be other than glutamatergic.

\section{Absence of PPE mRNA defines a class of NK1R-ir neurons that could be the hypothesized kernel of the pre-BötC respiratory rhythm generator}

Respiratory rhythm generation has long been attributed to reciprocal interactions between inhibitory neurons (Rybak et al., 1997; for review, see Feldman and McCrimmon, 1999). According to these models, the excitatory drive to this set of mutually inhibitory neurons is tonic (e.g., from chemoreceptors, state-dependent inputs) or caused by inward currents (e.g., $I_{\mathrm{h}}, I_{\mathrm{CaT}}$, reactivated by GABAergic or glycinergic hyperpolarization (Richter and Spyer, 2001). The central role of glutamatergic neurons in respiratory rhythmogenesis has only recently come to the fore. According to the pacemaker-driven network theory (Feldman and McCrimmon, 1999; Smith et al., 2000), glutamatergic interneurons, including a core of cells with intrinsic bursting properties, constitute the kernel of the respiratory rhythm generating circuit (Onimaru et al., 1995; Rekling and Feldman, 1998; Ballanyi et al., 1999; Del Negro et al., 2001; Johnson et al., 2001). The theory that NK1R immunoreactivity is a selective marker for the rhythmogenic neurons is based on the high level of these receptors in the pre-BötC, the excitatory effect of substance $\mathrm{P}$ on some inspiratory pre-BötC neurons in vitro, and the disruption of breathing caused by selective lesion of NK1R-ir cells (Gray et al., 1999, 2001). The present data add two pieces of evidence to the theory. First, VRG NK1R-ir cells are indeed predominantly glutamatergic, whereas most GABAergic and glycinergic VRG neurons are not NK1R-ir (H. Wang et al., 2001). Second, we found a subtype of NK1R-ir glutamatergic neuron without spinal projections that is present almost exclusively in the pre-BötC. These small fusiform neurons are likely to be functionally different from the large PPE mRNAexpressing NK1R-ir neurons because their somatic size and morphology are so different. Because of their location, the small fusiform NK1R-ir neurons that do not express PPE mRNA may be the adult version of the inspiratory substance P-sensitive neurons recorded in vitro (Gray et al., 1999). These cells are believed to be rhythmogenic and may have pacemaker properties (Feldman and McCrimmon, 1999; Pilowsky and Feldman, 2001). The discharge pattern of these NK1R-ir cells in vivo needs to be identified definitively. Candidates include some form of excitatory I-constant neurons that are sometimes viewed as antecedent to VRG I-AUG neurons (Duffin et al., 1995, 2000) or the preinspiratory cells of the pre-BötC shown by us previously to be NK1R-ir (Guyenet and Wang, 2001). However, further work is needed to determine whether the latter neurons are the small fusiform ones.

\section{The rVRG contains NK1R-ir neurons that are both glutamatergic and enkephalinergic and may be inspiratory premotor neurons}

The retrograde labeling experiments (Figs. 2, 3, 5) confirmed the presence of bulbospinal NK1R-ir neurons in the rVRG region, which is defined by its large concentration of neurons projecting to the $\mathrm{C} 4$ ventral horn. These NK1R-ir cells were shown to project to thoracic and cervical levels. All bulbospinal NK1R-ir neurons contained VGLUT2 mRNA in one experiment and PPE mRNA in the other; thus they are both glutamatergic and enkephalinergic. Several precedents for this unusual combination of transmitters exist in the pontomedullary region (Van Bockstaele et al., 2000; Stornetta et al., 2001, 2002b).

The combination of a glutamatergic phenotype, location in the rVRG, and projection to the phrenic motor nucleus suggested to us that some of the bulbospinal NK1R-ir cells might be inspiratory neurons. Accordingly, some of the I-AUG bulbospinal neurons exhibited high levels of NK1R immunoreactivity (Fig. $8 C, D)$. In agreement with the retrograde labeling experiments (Figs. 2, 3, 5), most bulbospinal I-AUG neurons of the rVRG did not express NK1R (Figs. 8 $A, B, 9$ ). This observation agrees with the fact that many inspiratory premotor neurons survive after lesion of VRG NK1R-ir neurons (Gray et al., 2001).

The NK1R-ir I-AUG neurons required a high level of respiratory drive to be activated (Fig. 6B1,B2). Most of these highthreshold cells could be silent at rest, which may account for the small number of NK1R-ir cells encountered in our initial experiments. The physiological role of the NK1R-ir high-threshold I-AUG neurons remains to be clarified. Judging from their firing pattern, location, and spinal projections, these cells could be inspiratory premotor neurons that innervate both phrenic and inspiratory intercostal motor neurons, but their projections to the thoracic spinal cord could also suggest a role in controlling vasomotor sympathetic efferents.

\section{Putative role of the enkephalinergic NK1R-ir neurons without spinal projections}

Although large injections of FG into a single spinal segment cannot possibly label all bulbospinal neurons, the present experiments clearly demonstrate that most of the large enkephalinergic NK1R-ir neurons of the VRG are not bulbospinal. Indeed, regardless of the site of injection (thoracic or cervical), FGlabeled NK1R-ir neurons were found exclusively caudal to bregma level $-12.6 \mathrm{~mm}$. The NK1R-ir neurons located rostral to that point therefore cannot be bulbospinal, and they clearly reside within the pre-BötC. Because the spinally projecting enkephalinergic NK1R-ir cells appear to be a form of inspiratory premotor neuron, we propose, by analogy, that those without spinal projections may be other forms of respiratory glutamatergic premotor neurons. Candidates could be the NK1R-ir pre-I/ I-DEC of the pre-BötC (Guyenet and Wang, 2001) that do not 
project to the cord (Sun et al., 1998; P. Guyenet and H. Wang, unpublished results) and have a discharge pattern that is theoretically consistent with a role as laryngeal premotor neurons.

Because only a fraction of the bulbospinal I-AUG neurons express NK1R, it is possible that the presence of this receptor does not provide diagnostic identification of functionally homogeneous classes of respiratory cells. Instead, NK1R immunoreactivity may be expressed by restricted subpopulations of neurons that belong to different functional groups. If this is true, the differential expression of NK1R in the VRG may exist to produce a specific respiratory response pattern to substance $\mathrm{P}$ release.

\section{Conclusion and physiological significance}

The respiratory stimulant effect of substance $\mathrm{P}$ is mediated in part by NK1 receptors (Chen et al., 1990; Monteau et al., 1996) and is observed in medullary slices and individual respiratory-related neurons of the pre-BötC (Johnson et al., 1996; Monteau et al., 1996; Gray et al., 1999). The association of NK1 receptors with glutamatergic neurons explains satisfactorily the respiratory stimulation produced by substance $\mathrm{P}$ administered in the ventrolateral medulla. The increase in respiratory rate and amplitude (Gray et al., 1999) may be achieved by simultaneous activation of several types of NK1R-ir neurons, including rhythmogenic cells and selected subpopulations of excitatory premotor neurons.

The pre-BötC, like the neighboring $\mathrm{C} 1$ area, probably receives substance P-containing inputs from serotonergic neurons that are activated by acidification (Milner et al., 1996; W. G. Wang et al., 2001). Central hypercapnia could thus stimulate respiration by depolarizing pre-BötC glutamatergic neurons via substance $\mathrm{P}$ released from raphe neurons. Nociceptive or muscle metabotropic afferents may also trigger the release of substance $\mathrm{P}$ into the VRG from spinoreticular neurons (Potts et al., 1999; Gamboa-Esteves et al., 2001).

\section{REFERENCES}

Aihara Y, Mashima H, Onda H, Hisano S, Kasuya H, Hori T, Yamada S, Tomura H, Yamada Y, Inoue I, Kojima I, Takeda J (2000) Molecular cloning of a novel brain-type $\mathrm{Na}(+)$-dependent inorganic phosphate cotransporter. J Neurochem 74:2622-2625.

Auger C, Atwell D (2000) Fast removal of synaptic glutamate by postsynaptic transporters. Neuron 28:547-558.

Bai L, Xu H, Collins JF, Ghishan FK (2001) Molecular and functional analysis of a novel neuronal vesicular glutamate transporter. J Biol Chem 276:36764-36769.

Ballanyi K, Onimaru H, Homma K (1999) Respiratory network function in the isolated brainstem-spinal cord of newborn rats. Prog Neurobiol 59:583-634.

Brown JL, Liu H, Maggio JE, Vigna SR, Mantyh PW, Basbaum AI (1995) Morphological characterization of substance P receptorimmunoreactive neurons in the rat spinal cord and trigeminal nucleus caudalis. J Comp Neurol 356:327-344.

Butera Jr RJ, Rinzel J, Smith JC (1999a) Models of respiratory rhythm generation in the pre-Botzinger complex. I. Bursting pacemaker neurons. J Neurophysiol 82:382-397.

Butera Jr RJ, Rinzel J, Smith JC (1999b) Models of respiratory rhythm generation in the pre-Botzinger complex. II. Populations of coupled pacemaker neurons. J Neurophysiol 82:398-415.

Chen Z, Hedner J, Hedner T (1990) Local effects of substance P on respiratory regulation in the rat medulla oblongata. J Appl Physiol 68:693-699.

Chitravanshi VC, Sapru HN (1999) Phrenic nerve responses to chemical stimulation of the subregions of ventral medullary respiratory neuronal group in the rat. Brain Res 821:443-460.

Connelly CA, Dobbins EG, Feldman JL (1992) Pre-Bötzinger complex in cats: respiratory neuronal discharge patterns. Brain Res 590:337-340.

Del Negro CA, Johnson SM, Butera RJ, Smith JC (2001) Models of respiratory rhythm generation in the pre-Botzinger complex. III. Experimental tests of model predictions. J Neurophysiol 86:59-74.

Dobbins EG, Feldman JL (1994) Brainstem network controlling descending drive to phrenic motoneurons in rat. J Comp Neurol 347:64-86.

Dong X-W, Feldman JL (1995) Modulation of inspiratory drive to phrenic motoneurons by presynaptic adenosine $\mathrm{A}_{1}$ receptors. J Neurosci 15:3458-3467.

Dong XW, Morin D, Feldman JL (1996) Multiple actions of 1S,3RACPD in modulating endogenous synaptic transmission to spinal respiratory motoneurons. J Neurosci 16:4971-4982.

Duffin J, Ezure K, Lipski J (1995) Breathing rhythm generation: focus on the rostral ventrolateral medulla. News Physiol Sci 10:133-140.

Duffin J, Tian GF, Peever JH (2000) Functional synaptic connections among respiratory neurons. Respir Physiol 122:237-246.

Ellenberger HH, Feldman JL (1990) Subnuclear organization of the lateral tegmental field of the rat. I: Nucleus ambiguus and ventral respiratory group. J Comp Neurol 294:202-211.

Feldman JL, McCrimmon DR (1999) Neural control of breathing. In: Fundamental neuroscience (Zigmond MJ, Bloom FE, Landis SC, Roberts JL, Squire LR, eds), pp 1063-1090. San Diego: Academic.

Fong TM, Anderson SA, Yu H, Huang RR, Strader CD (1992) Differential activation of intracellular effector by two isoforms of human neurokinin-1 receptor. Mol Pharmacol 41:24-30.

Fremeau Jr RT, Troyer MD, Pahner I, Nygaard GO, Tran CH, Reimer RJ, Bellocchio EE, Fortin D, Storm-Mathisen J, Edwards RH (2001) The expression of vesicular glutamate transporters defines two classes of excitatory synapse. Neuron 31:247-260.

Gamboa-Esteves FO, Kaye JC, McWilliam PN, Lima D, Batten TFC (2001) Immunohistochemical profiles of spinal lamina I neurones retrogradely labeled from the nucleus tractus solitarii in rat suggest excitatory projections. Neuroscience 104:523-538.

Gray PA, Rekling JC, Bocchiaro CM, Feldman JL (1999) Modulation of respiratory frequency by peptidergic input to rhythmogenic neurons in the Pre-Bötzinger complex. Science 286:1566-1568.

Gray PA, Janczewski WA, Mellen N, McCrimmon DR, Feldman JL (2001) Normal breathing requires pre-Botzinger complex neurokinin-1 receptor-expressing neurons. Nat Neurosci 4:927-930.

Guyenet PG, Wang H (2001) Pre-Bötzinger neurons with preinspiratory discharges "in vivo" express NK1 receptors in the rat. J Neurophysiol 86:438-446.

Ito M (2001) Cerebellar long-term depression: characterization, signal transduction, and functional roles. Physiol Rev 81:1143-1195.

Johnson SM, Smith JC, Funk GD, Feldman JL (1994) Pacemaker behavior of respiratory neurons in medullary slices from neonatal rat. J Neurophysiol 72:2598-2608.

Johnson SM, Smith JC, Feldman JL (1996) Modulation of respiratory rhythm in vitro: role of $\mathrm{G}_{\mathrm{i} / \mathrm{o}}$ protein-mediated mechanisms. J Appl Physiol 80:2120-2133.

Johnson SM, Koshiya N, Smith JC (2001) Isolation of the kernel for respiratory rhythm generation in a novel preparation: the preBötzinger complex "island.” J Neurophysiol 85:1772-1776.

Li H, Leeman SE, Slack BE, Hauser G, Saltsman WS, Krause JE, Blusztajn JK, Boyd ND (1997) A substance P (neurokinin-1) receptor mutant carboxyl-terminally truncated to resemble a naturally occurring receptor isoform displays enhanced responsiveness and resistance to desensitization. Proc Natl Acad Sci USA 94:9475-9480.

Lieske SP, Thoby-Brisson M, Telgkamp P, Ramirez JM (2000) Reconfiguration of the neural network controlling multiple breathing patterns: eupnea, sighs and gasps. Nat Neurosci 3:600-607.

Lipski J (1981) Antidromic activation of neurones as an analytical tool in the study of the central nervous system. J Neurosci Methods 4:1-32.

Liu YY, Ju G, Wong-Riley MTT (2001) Distribution and colocalization of neurotransmitters and receptors in the pre-Botzinger complex of rats. J Appl Physiol 91:1387-1395.

Milner TA, Reis DJ, Giuliano R (1996) Afferent sources of substance P in the $\mathrm{C} 1$ area of the rat rostral ventrolateral medulla. Neurosci Lett 205:37-40.

Monteau R, Ptak K, Broquère N, Hilaire G (1996) Tachykinins and central respiratory activity: an in vitro study on the newborn rat. Eur J Pharmacol 314:41-50.

Nakaya Y, Kaneko T, Shigemoto R, Nakanishi S, Mizuno N (1994) Immunohistochemical localization of substance $\mathrm{P}$ receptor in the central nervous system of the adult rat. J Comp Neurol 347:249-274.

Onimaru H, Arata A, Homma I (1995) Intrinsic burst generation of preinspiratory neurons in the medulla of brainstem-spinal cord preparations isolated from newborn rats. Exp Brain Res 106:57-68.

Paxinos G, Watson C (1998) The rat brain in stereotaxic coordinates. San Diego: Academic.

Pilowsky PM, Feldman JL (2001) Identifying neurons in the preBotzinger complex that generate respiratory rhythm: visualizing the ghost in the machine. J Comp Neurol 434:125-127.

Pinault D (1996) A novel single-cell staining procedure performed in vivo under electrophysiological control: morpho-functional features of juxtacellularly labeled thalamic cells and other central neurons with biocytin or Neurobiotin. J Neurosci Methods 65:113-136.

Potts JT, Fuchs IE, Li JH, Leshnower B, Mitchell JH (1999) Skeletal muscle afferent fibres release substance $\mathrm{P}$ in the nucleus tractus solitarii of anaesthetized cats. J Physiol (Lond) 514:829-841.

Rao SM, Howells RD (1992) Molecular cloning, sequence analysis and 
translation of proenkephalin mRNA from rat heart. Regul Pept 40:397-408.

Rekling JC, Feldman JL (1998) Pre-Bötzinger complex and pacemaker neurons: hypothesized site and kernel for respiratory rhythm generation. Annu Rev Physiol 60:385-405.

Rekling JC, Shao XM, Feldman JL (2000) Electrical coupling and excitatory synaptic transmission between rhythmogenic respiratory neurons in the pre-Botzinger complex. J Neurosci 20:RC113(1-5).

Richter DW, Spyer KM (2001) Studying rhythmogenesis of breathing: comparison of in vivo and in vitro models. Trends Neurosci 24:464-472.

Rybak IA, Paton JF, Schwaber JS (1997) Modeling neural mechanisms for genesis of respiratory rhythm and pattern. II. Network models of the central respiratory pattern generator. J Neurophysiol 77:2007-2026.

Schmued LC, Fallon JH (1986) Fluoro-gold: a new fluorescent retrograde axonal tracer with numerous unique properties. Brain Res 377:147-154.

Schreihofer AM, Guyenet PG (1997) Identification of C1 presympathetic neurons in rat rostral ventrolateral medulla by juxtacellular labeling in vivo. J Comp Neurol 387:524-536.

Schreihofer AM, Stornetta RL, Guyenet PG (1999) Evidence for glycinergic respiratory neurons: Bötzinger neurons express mRNA for glycinergic transporter 2. J Comp Neurol 407:583-597.

Schwarzacher SW, Smith JC, Richter DW (1995) Pre-Bötzinger complex in the cat. J Neurophysiol 73:1452-1461.

Smith JC, Ellenberger HH, Ballanyi K, Richter DW, Feldman JL (1991) Pre-Botzinger complex: a brainstem region that may generate respiratory rhythm in mammals. Science 254:726-729.

Smith JC, Butera RJ, Koshiya N, Del Negro C, Wilson CG, Johnson SM (2000) Respiratory rhythm generation in neonatal and adult mammals: the hybrid pacemaker-network model. Respir Physiol 122:131-147.

Solomon IC, Edelman NH, Neubauer JA (1999) Patterns of phrenic motor output evoked by chemical stimulation of neurons located in the pre-Botzinger complex in vivo. J Neurophysiol 81:1150-1161.

Solomon IC, Edelman NH, O'Neill MH (2000) $\mathrm{CO}_{2} / \mathrm{H}^{+}$chemorecep- tion in the cat pre-Botzinger complex in vivo. J Appl Physiol 88:1996-2007.

Stornetta RL, Guyenet PG (1999) Distribution of glutamic acid decarboxylase mRNA-containing neurons in rat medulla projecting to thoracic spinal cord in relation to monoaminergic brainstem neurons. J Comp Neurol 407:367-380.

Stornetta RL, Schreihofer AM, Pelaez NM, Sevigny CP, Guyenet PG (2001) Preproenkephalin mRNA is expressed by $\mathrm{C} 1$ and non-C1 barosensitive bulbospinal neurons in the rostral ventrolateral medulla of the rat. J Comp Neurol 435:111-126.

Stornetta RL, Sevigny CP, Guyenet PG (2002a) Vesicular glutamate transporter DNPI/VGLUT2 mRNA is present in C1 and several other groups of brainstem catecholaminergic neurons. J Comp Neurol 444:191-206.

Stornetta RL, Sevigny CP, Schreihofer AM, Rosin DL, Guyenet PG (2002b) Vesicular glutamate transporter DNPI/VGLUT2 mRNA is expressed by both $\mathrm{C} 1$ adrenergic and non-aminergic presympathetic vasomotor neurons of the rat. J Comp Neurol 444:207-220.

Sun Q-J, Goodchild AK, Chalmers JP, Pilowsky PM (1998) The preBötzinger complex and phase-spanning neurons in the adult rat. Brain Res 809:204-213.

Takamori S, Rhee JS, Rosenmund C, Jahn R (2000) Identification of a vesicular glutamate transporter that defines a glutamatergic phenotype in neurons. Nature 407:189-194.

Van Bockstaele EJ, Saunders A, Commons KG, Liu XB, Peoples J (2000) Evidence for coexistence of enkephalin and glutamate in axon terminals and cellular sites for functional interactions of their receptors in the rat locus coeruleus. J Comp Neurol 417:103-114.

Wang H, Stornetta RL, Rosin DL, Guyenet PG (2001) Neurokinin-1 receptor-immunoreactive neurons of the ventral respiratory group in the rat. J Comp Neurol 434:128-146.

Wang WG, Tiwari JK, Bradley SR, Zaykin AV, Richerson GB (2001) Acidosis-stimulated neurons of the medullary raphe are serotonergic. J Neurophysiol 85:2224-2235. 